\title{
A Hydrogen Peroxide Sensor Prepared by Electropolymerization of Pyrrole Based on Screen-Printed Carbon Paste Electrodes
}

\author{
Guang $\mathrm{Li}^{1}{ }^{1, *}$, You Wang ${ }^{2}$ and Hui $\mathrm{Xu}^{1}$ \\ 1 National Laboratory of Industrial Control Technology, Zhejiang University, Hangzhou 310027, P.R. \\ China \\ Tel: +86-13558068126, Fax: +86-571-87952233-8228, E-mail: guangli @zju.edu.cn (Guang Li). \\ E-mail: hxu2@iipc.zju.edu.cn (Hui Xu) \\ 2 Department of Biomedical Engineering, Zhejiang University, Hangzhou 310027, P.R. China \\ E-mail: king_wy@zjuem.zju.edu.cn
}

* Author to whom correspondence should be addressed.

Received: 5 January 2007 / Accepted: 28 February 2007 / Published: 5 March 2007

\begin{abstract}
A disposable amperometric biosensor for commercial use to detect hydrogen peroxide has been developed. The sensor is based on screen-printed carbon paste electrodes modified by electropolymerization of pyrrole with horseradish peroxidase (HRP) entrapped. The facture techniques of fabricating the enzyme electrodes are suitable for mass production and quality control. The biosensor shows a linear amperometric response to $\mathrm{H}_{2} \mathrm{O}_{2}$ from 0.1 to $2.0 \mathrm{mM}$, with a sensitivity of $33.24 \mu \mathrm{A} \mathrm{mM} \mathrm{m}^{-1} \mathrm{~cm}^{-2}$. Different operational parameters of electropolymerization are evaluated and optimized.
\end{abstract}

Keywords: Electropolymerization; Biosensor; Polypyrrole; Horseradish Peroxidase; ScreenPrinted Electrodes

\section{Introduction}

The determination of hydrogen peroxide is of considerable interest, because hydrogen peroxide is not only an important analyte in food, pharmaceutical, clinical, industrial and environmental analyses but also playing a key role as the product of the enzymatic reaction in coupled enzyme systems [1]. Several analytical techniques have been employed for this determination, such as titrimetry [2], 
spectrometry [3], chemiluminescene [4, 5], but these techniques suffer from interferences, long analysis time and use of expensive reagents. Electroanalytical methods [6-11] have also been found suitable since they achieve low detection limits and rapid response time. Coupled with enzymatic reactions, it is promising for fabrication of simple and low-cost enzyme sensors. Until now, horseradish peroxidase (HRP) has become a commonly used enzyme to construction hydrogen peroxide biosensors.

It is well known that direct electron transfer from the reduced enzyme to a distant electrode is negligible. To improve it, redox enzyme catalysis can be mediated by a variety of organic and inorganic species which act efficiently in competition with the natural acceptors (or donors) of electrons [12]. The most widely used mediators are ferrocene derivatives [9, 13], although other types are employed [14].

The technique to immobilize the enzyme is one of the key issues in developing a reliable biosensor. Many strategies have been used including direct adsorption, crosslinking with glutaraldehyde, covalent binding, and entrapment in polymerized films or gels [15]. As carrier material in immobilizing enzyme, conducting polymers have been receiving great and broad interests. The immobilization of an enzyme into an electropolymerized film offers many attractive features since the process is instrumentally controlled and an enzyme electrode can be easily prepared in a rapid one-step procedure. The most popular conducting polymers for the immobilization of enzyme are polypyrrole (PPy) [16, 17], polyaniline [18] and polythiophene Especially, PPy and its derivatives are most widely used for entrapping enzyme, because PPy can be easily electrodeposited onto an electrode surface from aqueous solutions, which are compatible with most biological elements [15, 19].

Many researches indicated that the enzyme can be entrapped by PPy matrix immobilized on the surface of Pt, Au and glassy carbon (GC) electrodes. But electropolymerization on the surface of screen-printed carbon paste electrodes has been few reported. Screen-printing technology is a low-cost technology which allows depositing thick films (a few to hundreds of micrometers) and is well suited for mass production and portable devices [20]. They allow fast and easy monitoring. For example, disposable screen-printed enzyme strips are widely used by diabetic patients for self-monitoring of their blood glucose levels [21]. Such a microfabrication route offers high-volume production of extremely inexpensive and yet highly reproducible disposable enzyme electrodes.

In this paper, the fabrication of a disposable hydrogen peroxide amperometric biosensor based on screen-printing technology was described. Carbon and silver ink were used to form electrodes while silver was employed as conductive lead. HRP was immobilized in a PPy film electropolymerized on the surface of screen-printed carbon paste electrodes. Potassium ferrocyanide was deposited as electron transfer mediator to facilitate efficient electron transfer. The biosensor can determine hydrogen peroxide concentration using only $1 \mu \mathrm{L}$ sample. Different operational parameters influencing the biosensor response, i.e. monomer, electrolyte and HRP concentrations, PPy film growth rate and thickness were evaluated and optimized. 


\section{Experimental}

\subsection{Materials and apparatus}

HRP (>300 U/mg) was purchased from Qiude Biochemical Engineering CO., Ltd., China. Hydrogen peroxide $(30 \%, \mathrm{w} / \mathrm{w})$, pyrrole $(98 \%)$, potassium ferrocyanide, lithium perchlorate $\left(\mathrm{LiClO}_{4}\right)$ and other chemicals were of analytical grade without further purification. Carbon paste (Jelcon $\mathrm{CH}-10$ ) was purchased from Jujo Chemical CO., Ltd., Japan. Double-distilled water was used in all experiments.

$0.25 \mathrm{M}$ hydrogen peroxide standard solution was prepared every three days and stored at room temperature without light. Diluted hydrogen peroxide standard solutions were freshly prepared directly prior to use, carried out in a $0.2 \mathrm{M}$ phosphate buffered saline (PBS) solution ( $\mathrm{pH} 7.0$ ) containing $0.2 \mathrm{M}$ $\mathrm{NaCl}$.

Amperometric measurements were performed by a CHI760B Electrochemical Work Station $(\mathrm{CH}$ Instrument Inc., USA). During the electropolymerization, a platinum disk $\left(2 \mathrm{~mm}^{2}\right)$ and $\mathrm{Ag} / \mathrm{AgCl}$ were used as counter and reference electrodes, respectively. The electrodes were screen-printed using a MT750A screen printing machine (Ming Tai Screen Printing Machine CO., Ltd., Taiwan)

\subsection{Electrode preparation}

Screen-printed electrodes were fabricated on polypropylene (PP) sheets using the screen-printer. Three masks were used to form sliver conducting lead wires, carbon paste film for electrochemical reaction and insulating film, the process has been described in detail previously [22]. The structure of the biosensor is shown in Figure 1, consisting of an $\mathrm{Ag} / \mathrm{AgCl}$ pseudo-reference electrode and two carbon electrodes, which acting as working and counter electrodes, respectively. The function of the silver leads was to improve electric conductivity of the electrodes. The reaction area was defined by the insulating film covering on the carbon paste film. The size of working electrode in reaction area was 1 $\mathrm{mm} \times 2 \mathrm{~mm}$ while the sensor substrate was $35 \mathrm{~mm} \times 10 \mathrm{~mm}$.

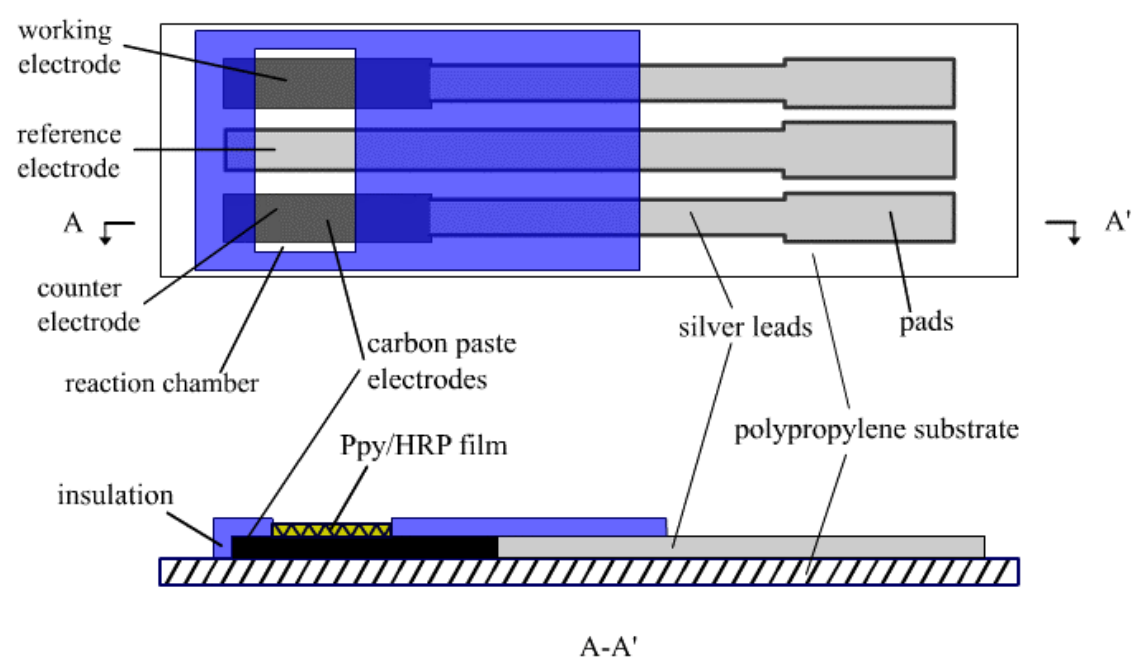

Figure 1. The structure of the screen-printed electrodes, the sensor substrate was $35 \mathrm{~mm} \times 10 \mathrm{~mm}$ while the working electrode area was $1 \mathrm{~mm} \times 2 \mathrm{~mm}$. 


\subsection{Fabrication of enzyme electrode}

The hydrogen peroxide biosensor was fabricated by electropolymerization in a $5 \mathrm{~mL} 0.2 \mathrm{M}$ PBS solution ( $\mathrm{pH} 7.0$ ) containing $0.075 \mathrm{M}$ pyrrole, $0.075 \mathrm{M} \mathrm{LiClO}_{4}$ and $0.8 \mathrm{mg} / \mathrm{mL} \mathrm{HRP}$. One of the screen-printed carbon paste electrodes was used as working electrode while the platinum disk and $\mathrm{Ag} / \mathrm{AgCl}$ were used as counter and reference electrodes, respectively. Electrochemical polymerization carried out potentiostatically at $+1 \mathrm{~V}$ vs. $\mathrm{Ag} / \mathrm{AgCl}$ until a final optimum charge deposit $\left(50 \mathrm{mC} / \mathrm{cm}^{2}\right)$ was reached. The electrodes were washed and rinsed in double-distilled water to remove the unfixed enzyme and then were dried at room temperature. Subsequently $1 \mu \mathrm{L}$ PBS solution (pH 7.0) containing $0.1 \mathrm{M}$ potassium ferrocyanide was coated on reaction area uniformly and dried at room temperature in dark. For comparison, a biosensor was fabricated in a similar way except the HRP (2 mg/mL) was immobilized by physical adsorption.

\subsection{Measurement}

Amperometric measurements were carried out using a CHI760B electrochemical workstation. The working potential was $-300 \mathrm{mV}$ vs. the screen-printed $\mathrm{Ag} / \mathrm{AgCl}$ pseudo-reference electrode, $1 \mu \mathrm{L}$ hydrogen peroxide standard solution was dropped onto reaction area of enzyme electrode uniformly. Current-time curves of the amperometry were recorded using an IBM PC compatible computer via a RS232 series port communicating to the electrochemical workstation at room temperature. The response time of the sensors, time needed to reach a plateau corresponding to the steady state when the testing sample was added, was 40 seconds. The response current to $\mathrm{H}_{2} \mathrm{O}_{2}$ was determined by subtracting the background current from the observed current. The calibration curve was obtained with testing samples of different hydrogen peroxide concentration to investigate the characteristics of the biosensor to determine hydrogen peroxide concentration.

\section{Results and discussions}

\subsection{Optimization of the electropolymerization}

The sensitivity of a hydrogen peroxide biosensor depends on the activity of the immobilized HRP enzyme in the PPy film. The activities of the immobilized HRP enzyme were electrochemically analyzed.

In the presence of $1 \mu \mathrm{L} 1 \mathrm{mM} \mathrm{H}_{2} \mathrm{O}_{2}$ solution, the effects of pyrrole concentration, PPy film thickness, electropolymerization potential, $\mathrm{LiClO}_{4}$ concentration and $\mathrm{HRP}$ concentration on the response of the hydrogen peroxide biosensor were evaluated.

\subsubsection{Pyrrole concentration}

In potentiostatic electropolymerization mode, pyrrole monomer concentration is an important factor which influences the development of the polymer. A constant potential of $+1.0 \mathrm{~V} v \mathrm{vg} / \mathrm{AgCl}$ was 
applied to achieve the charge deposit of $50 \mathrm{mC} / \mathrm{cm}^{2}$, while various concentrations of pyrrole were used. Figure 2 shows the response current to $1 \mathrm{mM} \mathrm{H}_{2} \mathrm{O}_{2}$ of the sensors with the film electropolymerized using pyrrole of different concentration. Lower pyrrole concentration did not allow sufficient polymer formation and HRP entrapment onto the electrode surface. Optimized pyrrole concentration, $0.075 \mathrm{M}$, was selected in the experiments.

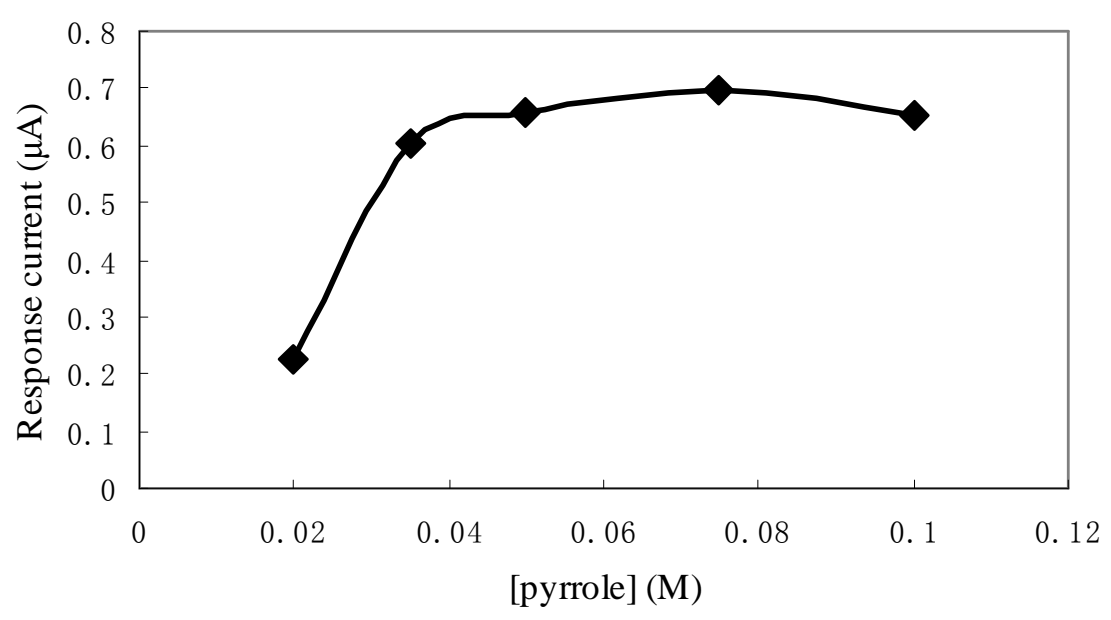

Figure 2. Effect of pyrrole concentration on response current to $1 \mathrm{mM} \mathrm{H} \mathrm{O}_{2}(1 \mu \mathrm{L},-300 \mathrm{mV}$ potential applied $)$.

\subsubsection{Density of charge deposit}

The thickness of the PPy film was determined by the charge deposited during electropolymerization. A thick PPy film could entrap much enzyme, but retard the analyte diffusion. In the research on a PPy glucose biosensor, the PPy film has been proven to act as a serious diffusion barrier, both the diffusion rates of glucose to the immobilized $\mathrm{GOx}$ and $\mathrm{H}_{2} \mathrm{O}_{2}$ to the platinum electrode were retarded severely by the polymer film [23]. However on hydrogen peroxide biosensors, Tatsuma indicated that the PPy film functioned as a conductive material, a part of the electrode material, and didn't retard the transport of the mediators [7]. Our experiment results are shown in Figure 3. When the charge deposited less than $25 \mathrm{mC} / \mathrm{cm}^{2}$, the response current (curve c) was very small because too little enzyme was entrapped. In the range from 50 to $150 \mathrm{mC} / \mathrm{cm}^{2}$, the response current to $\mathrm{H}_{2} \mathrm{O}_{2}$ changed due to the background current (curve b) increasing significantly though the observed current (curve a) remained almost unchanged. It was observed that although the thickness of PPy did not retard the transport of the mediators, it affected the amount of enzyme entrapped within the film and the background current to change the sensitivity of the sensor. In our experiments, the density of charge deposit of $50 \mathrm{mC} / \mathrm{cm}^{2}$ was selected. 


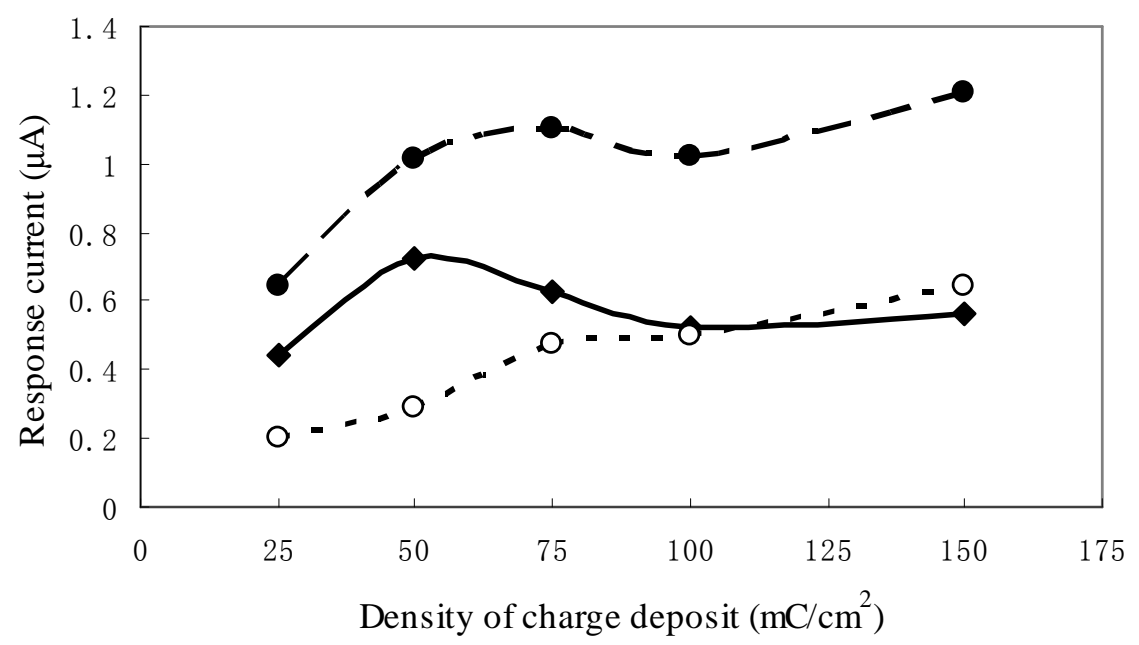

Figure 3. Effect of the density of charge deposit on (a) observed current; (b) background current and (c) response current to $1 \mathrm{H}_{2} \mathrm{O}_{2}(1 \mu \mathrm{L},-300 \mathrm{mV}$ potential applied).

\subsubsection{Potential for electropolymerization}

The effect of electropolymerization potential on enzyme electrode response was evaluated because the potential determined the growth rate of polymer film. With the increase of potential from $0.8 \mathrm{~V}$ to $1.2 \mathrm{~V}$, the peak current during electropolymerization process increased from 18 to $175 \mu \mathrm{A}$ to affect the sensitivity of the sensor, so that the electropolymerization potential should be optimized. When hydrogen peroxide concentration was $1 \mathrm{mM}$, the potential dependence of response current was shown in Figure 4. The results indicated that the maximum response current was obtained when electropolymerization potential was $1.0 \mathrm{~V}$, which was accordingly used in our experiments.

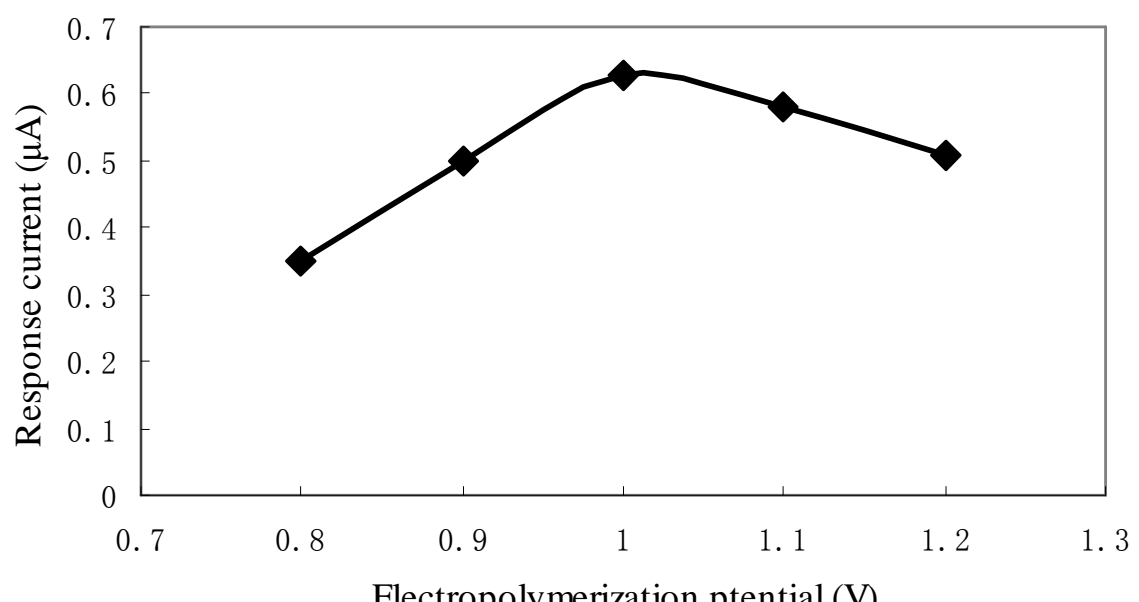

Figure 4. Effect of electropolymerization potential on response current to $1 \mathrm{mM} \mathrm{H}_{2} \mathrm{O}_{2}(1 \mu \mathrm{L},-300 \mathrm{mV}$ potential applied $)$. 


\subsection{4. $\mathrm{LiClO}_{4}$ concentration}

The electrolyte concentration should be high enough to facilitate the charge transfer in solution, but it should not compete with the pyrrole monomer cation radicals. Both $\mathrm{LiClO}_{4}$ and $\mathrm{KCl}$ were commonly used as electrolyte for pyrrole polymerization [6, 8, 24, 25]. Comparing both electrolytes, we used $\mathrm{LiClO}_{4}$ in the experiments due to its better catalyze effect besides the effect of $\mathrm{ClO}_{4}^{-}$doping. When $\mathrm{LiClO}_{4}$ concentration was within a range of 0.075 to $0.15 \mathrm{M}$, the electropolymerized enzyme sensor performed well, so the $\mathrm{LiClO}_{4}$ concentration of $0.075 \mathrm{M}$ was selected for our experiments.

\subsubsection{Enzyme concentration}

The HRP concentration in the pyrrole monomer solution for preparing the enzyme electrode was a key factor to affect the sensitivity, because the sensor response depended upon the amount of immobilized HRP. Figure 5 shows the response current to $1 \mathrm{mM} \mathrm{H}_{2} \mathrm{O}_{2}$ of the sensors using HRP of different concentration. With the increase of HRP concentration from $0.2 \mathrm{mg} / \mathrm{ml}$ to $0.8 \mathrm{mg} / \mathrm{ml}$, the response current was almost doubled. When the HRP concentration was higher than $0.8 \mathrm{mg} / \mathrm{ml}$, the response current of the sensor did not increase further. So the HRP concentration of $0.8 \mathrm{mg} / \mathrm{ml}$ was used in the experiments for the economic consideration.

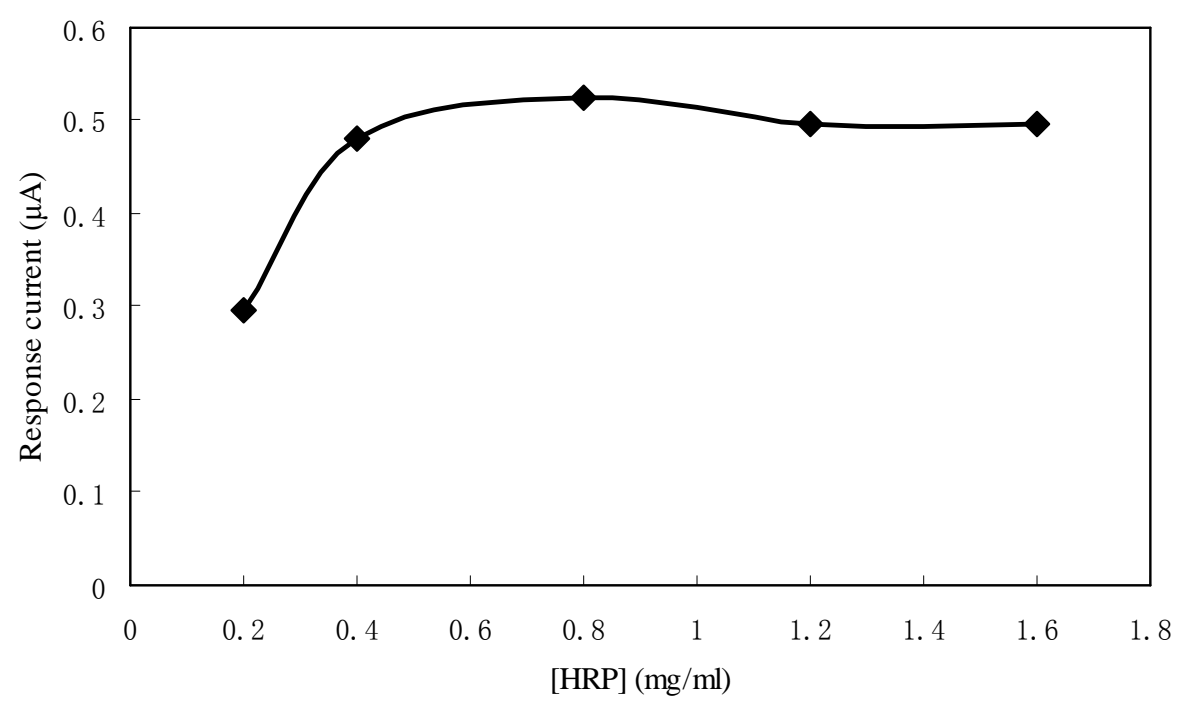

Figure 5. Effect of HRP concentration on response current to $1 \mathrm{mM} \mathrm{H}_{2} \mathrm{O}_{2}(1 \mu \mathrm{L},-300 \mathrm{mV}$ potential applied $)$.

\section{2. $p H$ and electrolyte influences on biosensor response}

The $\mathrm{pH}$ influence was investigated by amperometric measurement of $1 \mathrm{mM} \mathrm{H}_{2} \mathrm{O}_{2}$ in PBS $0.067 \mathrm{M}$ at different $\mathrm{pH}$ values between 5.0 and 9.0 as shown in Figure 6. The maximum response current was observed at pH 7.0 in agreement with Ref.[26]. In order to obtain the maximum bioactivity and optimal sensitivity, PBS solution of $\mathrm{pH} 7.0$ was selected for our experiments. 


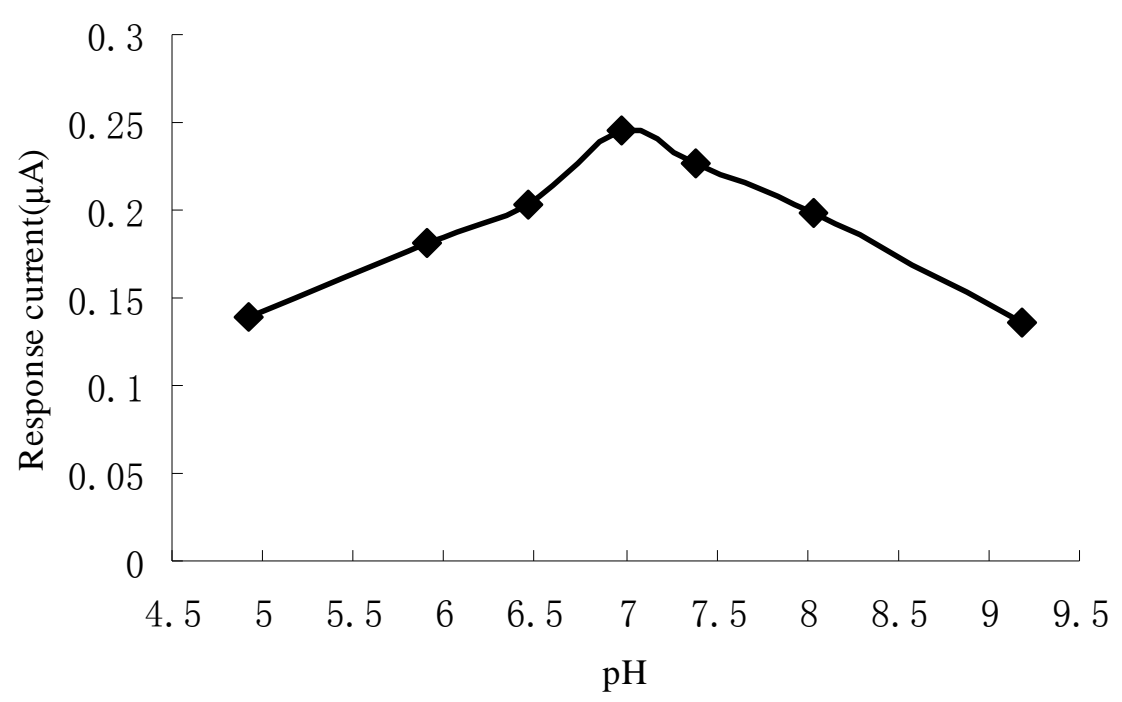

Figure 6. Effect of $\mathrm{pH}$ on response current to $1 \mathrm{mM} \mathrm{H}_{2} \mathrm{O}_{2}(1 \mu \mathrm{L},-300 \mathrm{mV}$ potential applied).

Phosphate $(0.033,0.067,0.1,0.2 \mathrm{M})$ was chosen to study the influence of electrolyte concentration. The results showed that the effect of phosphate concentration on the response was little. So 0.2 M PBS solution was selected in the subsequent experiments.

\subsection{Effect of ferrocyanide on the response current of the biosensor}

The ferrocyanide improves the charge transfer between the redox active site of the enzyme and the electrode, and should exhibit a fast electron exchange rate, while their electrochemical transformation usually takes place at low potentials to avoid the interference of other electroactive species normally present (e.g. ascorbic acid and uric acid). Figure 7 shows the cyclic voltammetry of the electrode in the absence (B) and presence (A) of ferrocyanide. Comparing Figures 7(A) and 7(B), it is obviously that with the presence of mediator, the reduce reaction took place at lower potentials ( $0 \mathrm{~V}$ vs. $-0.5 \mathrm{~V})$. From Figure 7(B), it indicated that without the ferrocyanide as mediator, biosensor response was likely caused by the direct electron transfer between HRP and PPy with subsequent reduction of the oxidized PPy. It's similar to those reported in previous literatures $[6,7]$. 


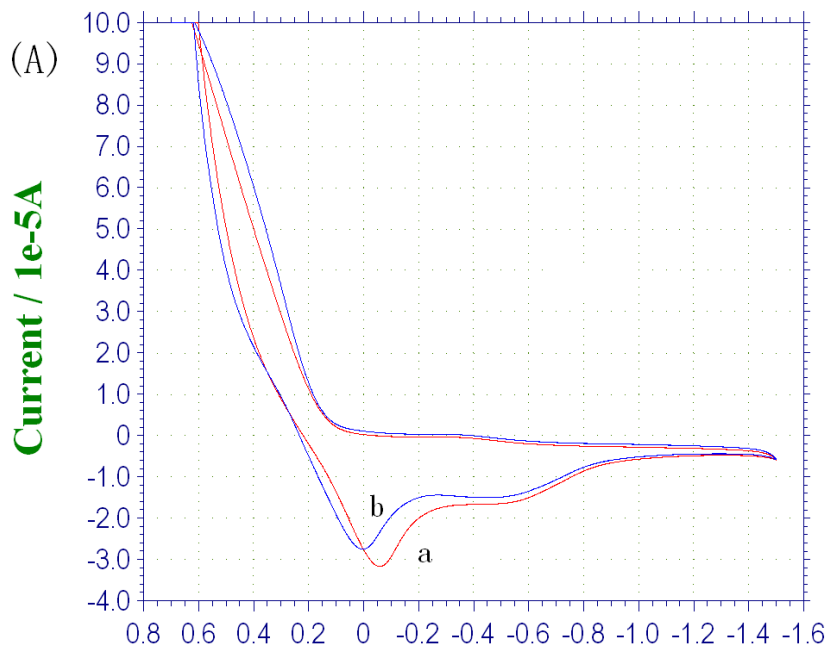

Potential / V

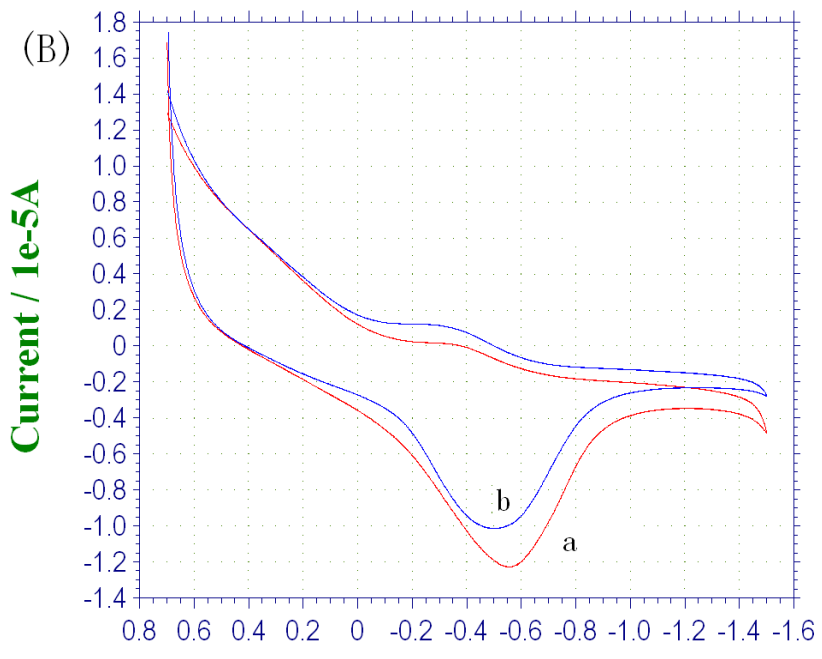

Potential / V

Figure 7. Cyclic voltammetry of the electrodes in the PBS solution (pH7.0). (A) electrodes modified with PPy/HRP/ ferrocyanide (B) electrodes modified with PPy/HRP.

(curve a-- with $1 \mathrm{mMH}_{2} \mathrm{O}_{2}$, curve b-- absence of $\mathrm{H}_{2} \mathrm{O}_{2}$.)

\subsection{Sensor characteristics}

The calibration curve of the sensor is shown as curve (a) in Figure 8. Eight hydrogen peroxide samples of different concentrations were measured using the biosensor fabricated under the optimized condition as described, and each sample of a certain concentration was measured five times. The inset illustration indicates the linear range of the PPy-HRP electrode response was from 0.1 to $2 \mathrm{mM}$, and the sensitivity corresponding to the linear range was about $33.24 \mu \mathrm{A} \mathrm{mM}^{-1} \mathrm{~cm}^{-2}$. The equation of the response was $\left[\mathrm{Y}(\mu \mathrm{A})=0.6647 \mathrm{X}(\mathrm{mM})-0.0234, \mathrm{R}^{2}=0.9953\right]$.

The reproducibility between electrodes represented by the relative standard deviation (R.S.D.) was measured. For all the $\mathrm{H}_{2} \mathrm{O}_{2}$ concentrations investigated, the average R.S.D. was $10.24 \%(\mathrm{n}=5)$.

The calibration curve of a sensor with HRP immobilized by physical adsorption is shown as curve (b) in Figure 8. Although the response of the electropolymerized sensor was a little lower than the one of the sensor with physically adsorbed HPR, the quantity of the HRP fixed in the PPy film can be relative easily adjusted by quantitatively controlling the electrical charge of polymerization. 


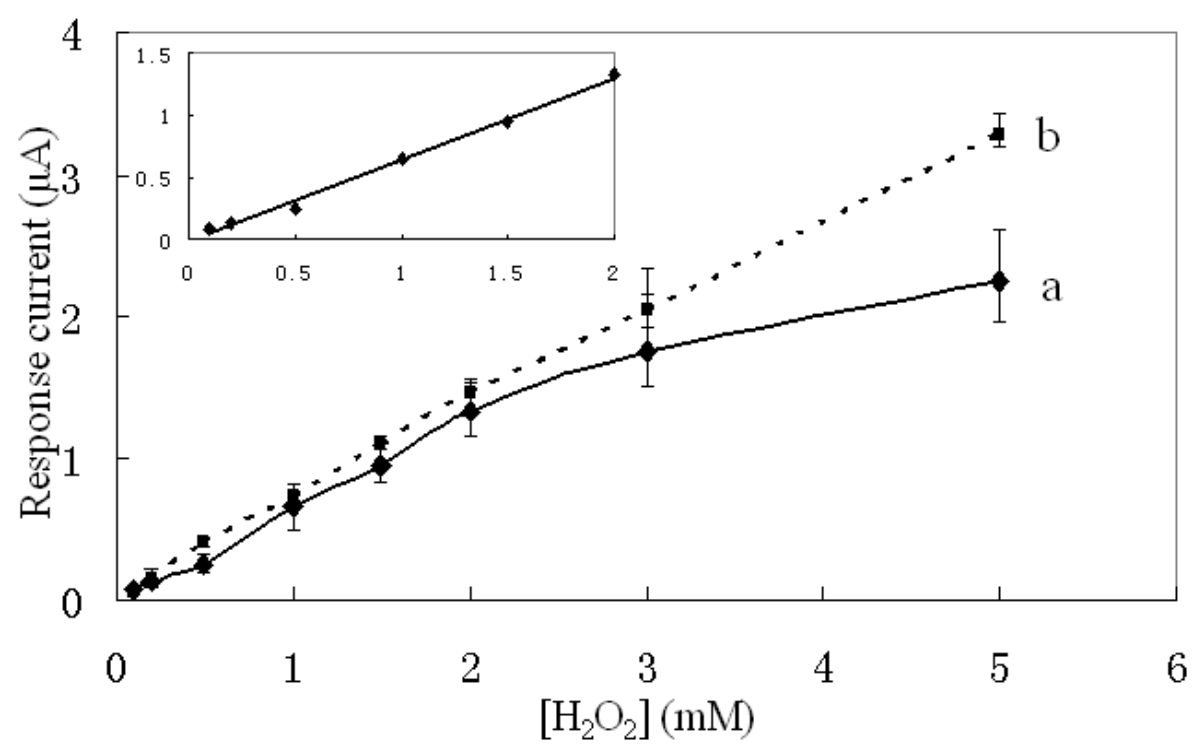

Figure 8. Calibration curve of $\mathrm{H}_{2} \mathrm{O}_{2}$ biosensor with HRP immobilized by (a) PPy film and (b) physical adsorption. The inset indicates calibration curve obtained for the linear range. Experimental condition: $1 \mu \mathrm{L} \mathrm{H}_{2} \mathrm{O}_{2},-300 \mathrm{mV}$ applied potential.

Different from previous researches reported, we electropolymerized PPy-HRP on a screen-printed carbon paste electrode rather than Pt or GC electrode [6, 27]. The sensor was developed for disposable use to allow quick and easy hydrogen peroxide monitor while only $1 \mu \mathrm{L}$ sample was required. The sensor exhibited a sensitivity of $33.24 \mu \mathrm{A} \mathrm{mM}^{-1} \mathrm{~cm}^{-2}$ which was higher than the hydrogen peroxide sensors reported in Ref.[6, 27] and allowed to be measured with a handheld meter conveniently.

\subsection{Sensor lifetime}

The operational stability was examined by measuring the response to $1 \mathrm{mM} \mathrm{H}_{2} \mathrm{O}_{2}$. The sensors were stored in 0.2 M PBS ( $\mathrm{pH} 7.0$ ) at 5 Celsius degree for 3 weeks, while measurements were conducted every 2 days during the first week and then once a week subsequently. The response did not change significantly.

\section{Conclusions}

A hydrogen peroxide biosensor with PPy-HRP electropolymerized on a screen-printed carbon paste electrode was studied. When the condition for electropolymerization was optimized, the sensor exhibited a sensitivity of $33.24 \mu \mathrm{A} \mathrm{mM} \mathrm{mm}^{-1} \mathrm{~cm}^{-2}$ to $\mathrm{H}_{2} \mathrm{O}_{2}$ with a linear range of 0.1 to $2 \mathrm{mM}$ while only 1 $\mu \mathrm{L}$ sample was required. This method is promising for manufacture of economic disposable hydrogen peroxide biosensors. 


\section{Acknowledgements}

This work has been funded by National Natural Science Foundation of China Grant \#60421002.

\section{References and Notes}

1. Ruzgas, T.; Csoregi, E.; Emneus, J.; Gorton, L.; Marko-Varga, G. Peroxidase-modified electrodes: fundamentals and application. Anal. Chim. Acta 1996, 330, 123-138.

2. Hurdis, E.C.; Hendrik Romeyn, J. Accuracy of determination of hydrogen peroxide by cerate oxidimetry. Anal. Chem. 1954, 26, 320-325.

3. Matsubara, C.; Kawamoto, N.; Takamura, K. Oxo[5, 10, 15, 20-tetra(4-pyridyl)porphyrinato] titanium(IV): an ultra-high sensitivity spectrophotometric reagent for hydrogen peroxide. Analyst 1992, 117, 1781-1784.

4. Aizawa, M.; Ikariyama, Y.; Kun, H. Photovoltaic determination of hydrogen peroxide with a biophotodiode. Anal. Lett. 1984, 17, 555-564.

5. Nakashima, K.; Maki, K.; Kawaguchi, S.; Akiyama, S.; Tsukamoto, Y.; Imai, K. Peroxyoxalate chemiluminescence assay of hydrogen peroxide and glucose using 2,4,6,8-tetrathiomorpholinopyrimido[5,4-d]pyrimidine as a fluorescent component. Anal. Sci. 1991, 7, 709.

6. Serradilla Razola, S.; Lopez Ruiz, B.; Mora Diez, N.; Mark Jr, H.B.; Kauffmann, J.M. Hydrogen peroxide sensitive amperometric biosensor based on horseradish peroxidase entrapped in a polypyrrole electrode. Biosens. Bioelectron. 2002, 17, 921-928.

7. Tatsuma, T.; Gondaira, M.; Watanabe, T. Peroxidase-incorporated polypyrrole membrane electrodes. Anal. Chem. 1992, 64, 1183-1187.

8. Thanachasai, S.; Rokutanzono, S.; Yoshida, S.; Watanabe, T. Novel hydrogen peroxide sensors based on peroxidase-carrying poly\{pyrrole-co-[4-(3-pyrrolyl)butanesulfonate]\}copolymer films. Anal. Sci. 2002, 18, 773-777.

9. Oungpipat, W.; Alexander, P.W.; Southwell-Keely, P. A reagentless amperometric biosensor for hydrogen peroxide determination based on asparagus tissue and ferrocene mediation. Anal. Chim. Acta 1995, 309, 35-45.

10. Wang, L.; Wang, E. A novel hydrogen peroxide sensor based on horseradish peroxidase immobilized on colloidal au modified ITO electrode. Electrochem. Commun. 2004, 6, 225-229.

11. Yang, Y.; Mu, S. Determination of hydrogen peroxide using amperometric sensor of polyaniline doped with ferrocenesulfonic acid. Biosens. Bioelectron. 2005, 21, 74-78.

12. Vidal, J.-C.; Garcia-Ruiz, E.; Castillo, J.-R. Recent Advances in Electropolymerized Conducting Polymers in Amperometric Biosensors. Microchim. Acta 2003, 143, 93.

13. Vidal, J.C.; Garcia, E.; Castillo, J.R. Development of a platinized and ferrocene-mediated cholesterol amperometric biosensor based on electropolymerization of polypyrrole in a flow system. Anal. Sci 2002, 18, 537-542.

14. Hong, M.Y.; Chang, J.Y.; Yoon, H.C.; Kim, H.S. Development of a screen-printed amperometric biosensor for the determination of L-lactate dehydrogenase level. Biosens. Bioelectron. 2002, 17, 13-18. 
15. Cosnier, S. Biosensors based on electropolymerized films: new trends. Anal. Bioanal. Chem. 2003, 377, 507-520.

16. Xue, H.; Mu, S. Bioelectrochemical response of the polypyrrole xanthine oxidase electrode. $J$. Electroanal. Chem. 1995, 397, 241.

17. Koopal, C.G.J.; Bos, A.A.C.M.; Nolte, R.J.M. Third-generation glucose biosensor incorporated in a conducting printing ink. Sens. Actuators B 1994, 18, 166.

18. Xue, H.; Shen, Z.; Li, C. Improved selectivity and stability of glucose biosensor based on in situ electropolymerized polyaniline-polyacrylonitrile composite film. Biosens. Bioelectron. 2005, 20, 2330-2334.

19. Vidal, J.C.; García, E.; Méndez, S.; Yarnoz, P.; Castillo, J.R. Three approaches to the development of selective bilayer amperometric biosensors for glucose by in situ electropolymerization. Analyst 1999, 124, 319-324.

20. Hart, J.P.; Crew, A.; Crouch, E.; Honeychurch, K.C.; Pemberton, R.M. Some recent designs and developments of screen-printed carbon electrochemical sensors/biosensors for biomedical, environmental, and Industrial analyses. Anal. Lett. 2004, 37, 789-830.

21. Newman, J.D.; Turner, A.P.F. Home blood glucose biosensors: a commercial perspective. Biosens. Bioelectron. 2005, 20, 2435-2453.

22. Li, G.; Ma, N.Z.; Wang, Y. A new handheld biosensor for monitoring blood ketones. Sens. Actuators B 2005, 109, 285-290.

23. Uang, Y.M.; Chou, T.C. Criteria for designing a polypyrrole glucose biosensor by galvanostatic electropolymerization. Electroanalysis 2002, 14, 1564-1570.

24. Da Silva, S.; Shan, D.; Cosnier, S. Improvement of biosensor performances for nitrate determination using a new hydrophilic poly(pyrrole-viologen) film. Sens. Actuators B 2004, 103, 397-402.

25. Vela, M.H.; De Jesus, D.S.; M., C.M.C.; Araujo, A.N.; Montenegro, M.C.B.S.M. Electroimmobilization of MAO into a polypyrrole film and its utilization for amperometric flow detection of antidepressant drugs. Electroanalysis 2003, 15, 133-138.

26. Harbury, H.A. Oxidation-reduction potentials of horseradish peroxidase. J. Biol. Chem. 1957, 225, 1009.

27. Gaspar, S.; Habermuller, K.; Csoregi, E.; Schuhmann, W. Hydrogen peroxide sensitive biosensor based on plant peroxidases entrapped in Os-modified polypyrrole films. Sens. Actuators B 2001, 72, 63-68.

(C) 2007 by MDPI (http://www.mdpi.org). Reproduction is permitted for noncommercial purposes. 